\title{
A critical appraisal on AIT in childhood asthma
}

\author{
Matteo Ferrando ${ }^{1,4+}$ (D), Francesca Racca ${ }^{2 \dagger}$, Lorena Nascimento Girardi Madeira ${ }^{2,3}$, Enrico Heffler ${ }^{2,4}$, \\ Giovanni Passalacqua ${ }^{1}$, Francesca Puggioni ${ }^{2,4}$, Niccolò Stomeo ${ }^{2}$ and Giorgio Walter Canonica ${ }^{2,4^{*}}$
}

\begin{abstract}
Abstract: Allergen immunotherapy (AIT) is the only disease-modifying treatment approved for allergic rhinitis and allergic asthma and represents a suitable therapeutic option, especially in childhood, to modify the progression of respiratory allergic diseases. Starting from the previous "generic class effect" evaluation, as testified by the numerous meta analyses, AIT is now considered a product-specific pathogenic-oriented treatment.

Background: AIT was empirically proposed more than one century ago in the subcutaneous form (SCIT), but the lgE-mediated mechanism of allergy was elucidated only after 50 years of clinical use of the treatment. The sublingual administration (SLIT) was developed during the 1980 ties, to achieve an improvement in safety and convenience. While SCIT is approved in the United States for the treatment of asthmatic patients with more than 12 years, so far few trials evaluated the clinical efficacy and safety of SLIT in children with allergic asthma, although the indications and some aspects remain unclear. Certainly, due to compliance problems, the age below 3 years may be reasonably considered a practical contraindication.

Conclusions: Given that some specific AIT products are effective and approved as drugs (AIFA, EMA, FDA), the use in children is still debated. Some aspects still need robust confirm: (a) the safety of AIT in asthma; (b) the optimal regimen of administration; (c) the role of AlT as preventative treatment for asthma development.
\end{abstract}

Keywords: Allergen immunotherapy, Subcutaneous, Children, SLIT, Allergic asthma, Class effect

\section{The previous view: the efficacy of AIT as product class}

Allergen immunotherapy is the only disease-modifying treatment approved for allergic rhinitis, allergic asthma and hymenoptera venom allergy [1]. Its use is also being investigated for food allergy and atopic dermatitis [2].

Allergen immunotherapy may also represent a valuable therapeutic option, especially in childhood, to modify the progression of respiratory allergic diseases [3]. This remains, indeed, is a unique characteristic of AIT, that is not shared by the standard pharmacological treatments, which only act on symptoms. In fact, AIT intervenes

\footnotetext{
*Correspondence: giorgio_walter.canonica@hunimed.eu

${ }^{\dagger}$ Matteo Ferrando and Francesca Racca equally contributed in planning and writing the paper

2 Personalized Medicine, Asthma and Allergy Clinic, Humanitas University and Research Hospital, Via Alessandro Manzoni 113, Rozzano, MI, Italy

Full list of author information is available at the end of the article
}

on the pathogenic mechanisms of the allergic disease themselves, by driving the immune system, through the exposure to increasingly higher doses of the etiological allergen(s), to develop a controlled immune response. Thus, so far AIT is the only curative treatment available for allergic diseases approved by the major regulatory authorities in the world including Food and Drug Administration (FDA) and European Medicines Agency (EMA) [4].

Researchers and clinicians are currently facing the era of the so-called "precision" or "personalized" medicine. In such a context, AIT is a good example of personalized therapeutic intervention, in which the most important variables for an appropriate selection of the right therapeutic strategy can be identified [5]. Moreover, in parallel with the refined knowledge of the pathogenic bases of allergic diseases, AIT can guarantee the most appropriate 
allocation of resources in this time of economical restrictions [6].

Allergen immunotherapy was early proposed in its subcutaneous form (SCIT, subcutaneous immunotherapy) more than one century ago [7]. The sublingual administration (SLIT) was later developed [8], leading to a relevant improvement in safety and convenience, with less frequent severe adverse events. In addition, SLIT allowed the patient's self-administration with a consequent reduction of the indirect costs.

The efficacy of AIT was grossly evaluated as a "class effect". This implied that also products with a poorly demonstrated scientific evidence of efficacy were included in meta analyses.

An example of this class effect is a study conducted from June 1999 to June 2000 which enrolled 159 adults and children with allergic asthma with multiple sensitization to grass pollens, tree pollens, weed pollens, animal dander, house-dust mites and moulds. All patients were treated with a standardized aqueous allergen extract in glycerol (ORALVAC, Bencard Allergie GmbH, Munich, Germany) using three concentrations at 100, 1.000 and 10.000 standardized oral units $(\mathrm{SOU}) / \mathrm{ml}$. The regimen began with one drop of the lowest concentration and ended with sixteen drops of the highest concentration. Following this incremental phase, a maintenance dose of 16 drops of the $10.000 \mathrm{SOU} / \mathrm{ml}$ formulation was administered three times a week for 4-6 months. The results of this study showed a statistically significant reduction in medication for all allergens sensitizations $(\mathrm{P}=.023) \mathrm{but}$ the asthma "variable" was not highlighted in this study [9].

Several double-blind randomized placebo-controlled clinical trials demonstrated the efficacy of Lais ${ }^{\circledR}$ (Lofarma), a carbamylated allergoid, in patients with HDM-induced allergic rhinitis with or without allergic asthma, proving a reduction in the total and individual symptoms and the drug consumption [10] (Table 1). Another clinical trial showed a reduction in bronchial hyperactivity, nasal inflammation assessed by nasal eosinophil count and asthma and rhinitis symptoms score in patients treated with three different doses of this carbamylated allergoid vs. placebo [11]. Only one clinical trial evaluated Lais administration to 28 children (mean age $13.3 \pm 2.1$ year) with HDM, Parietaria and Timothy grass-induced allergic rhinitis and/or asthma to verify the occurrence of immediate adverse reactions after an ultra-rush regimen exposure [12]. This study showed an excellent safety and tolerability profile but no other data on Lais in allergic children are at disposition.

Another study conducted from March 2004 to June 2005 evaluated the safety and the tolerability of an ultrarush method in 100 children (average age of 9.6 years) with allergic rhinitis, asthma, allergic conjunctivitis and atopic eczema. The investigators utilized standardized allergen extract solutions from Anallergo (Florence, Italy) and Staloral 300 from Stallergènes. Final data showed a high level of safety and tolerability for both the preparations [13].

Pollinex ${ }^{\circledR}$ Quattro (Allergy Therapeutics) is an ultrashort course specific immunotherapy (USCIT) vaccine containing glutaraldehyde-modified allergen extracts formulated with L-tyrosine and with the adjuvant monophosphoryl lipid A (MPL) administered as a preseasonal course of four injections. A total of 13 seasonal pollen allergens are extracted and processed to form a series of allergoids with the following dosage scheme: 300, 800, 2000 standardized units (SU) administered in a weekly $1 \mathrm{ml}$ injections, followed by a further top dose injection of $2000 \mathrm{SU}$ to complete the four injections course. Pollinex ${ }^{\circledR}$ Quattro has been evaluated in 3114 patients with multiple sensitization to pollens, 421 of which were children and adolescents $6-18$ years with seasonal allergic rhinitis, conjunctivitis and/or asthma. The length of this post-marketing surveillance study was 3 years. AIT was well accepted by children/adolescents and considered very good or good by $93 \%$ of the juvenile population. After the first treatment course, antiallergic medication use decreased from 83 to $24 \%$ of patients $(\mathrm{P}<.0001)$. Response to treatment was assessed as good or very good in $94 \%$ of patients and further improvements occurred in patients receiving subsequent courses of therapy [14].

Nowadays, it is recognized that each single product should be evaluated individually, as stated by the World Allergy Organization [15].

It is true that some issues and unmet needs remain critical: (a) at what age should the treatment be started? (b) for how many years does the treatment need to be maintained?; (c) does AIT really prevent the progression of respiratory allergy?; (d) a predictive biomarker of efficacy is required [16].

\section{AIT in children with allergic asthma}

A meta-analysis by Abramson et al. evaluated SCIT in allergic asthmatic patients, both adults and children. Overall, the results showed a significant clinical efficacy based on the standard parameters (symptoms, rescue medications usage, quality of life) [17]. Other available studies on the use SLIT in asthmatic children with mild to moderate HDM-induced asthma showed significant efficacy mainly in the reduction of symptoms and medication usage $[18,19]$. The more recent clinical trials in children with birch pollen and grass pollen allergic asthma, further confirmed the efficacy of SLIT in such conditions $[20,21]$. 


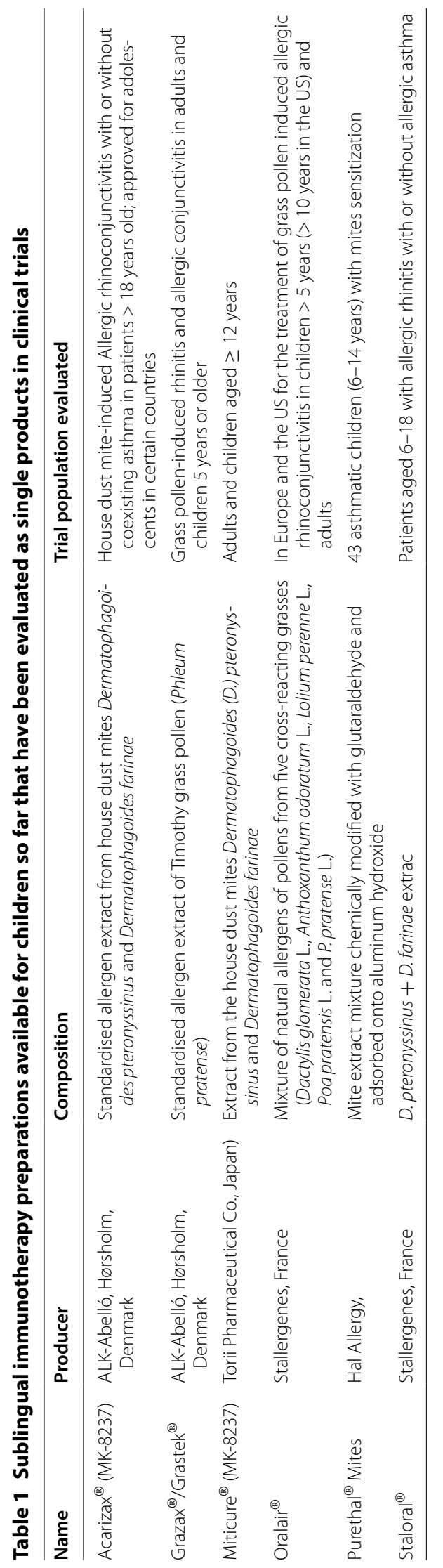


According to the more recent evidence, the international asthma documents now recommend a supportive role of AIT, as add on treatment to the standard of care [22]. Uncontrolled asthma remains an absolute contraindication for AIT [23].

The main and relevant aspect of AIT in children is the possible role of the treatment in reducing the risk of asthma onset and of new allergen sensitizations [24]. Children sensitized to one single allergen, as usually happens, when treated with AIT seem to develop new sensitizations at a lesser extent, but this is still matter of debate since the evidence remains poor [25, 26].

On the other hand, there were some randomized open clinical trials (one with SCIT and two with SLIT) showing a preventive effect to decrease the risk of asthma onset in allergic children with rhinitis. This phenomenon was recently confirmed in a randomized and double placebo controlled trial, showing that 2 years after discontinuation of AIT, there was a reduction in symptoms and medication usage [27].

\section{The current view: evaluation of the "single product"}

At present, the efficacy of AIT is no longer considered as a generic "class effect" and each AIT product is evaluated according to its scientific evidence (Table 2). This led to the approval of single AIT preparations by EMA and FDA [28].

In 2006 a total of 855 patients with grass pollen induced allergic rhinoconjunctivitis were randomized to placebo or $2.500,25.000$ or 75.000 once daily standardized quality (SQ) - grass allergen sublingual tablets (Grazax $^{\circledR} /$ Grastek $^{\circledR}$; ALK-Abelló, Hørsholm, Denmark). This pivotal trial showed a dose-related response with highest reductions in symptoms and medication utilization and improvements in quality of life (QoL) for the 75.000 SQ-T tablet [29]. Further studies confirmed these results in children [30]. Grazax ${ }^{\circledR} /$ Grastek $^{\circledR}$ is currently indicated for children $>5$ years and adults with allergic rhino conjunctivitis (Table 1).

Oralair $^{\circledR}$ (Stallergenes, France) is a mixture of natural allergens of pollens from five cross-reacting grasses (Dactylis glomerata L., Anthoxanthum odoratum L., Lolium perenne L., Poa pratensis L. and Phleum pratense L.). Oralair ${ }^{\circledR}$ is approved in Europe and the US for the treatment of grass pollen induced ARC in children $>5$ years ( $>10$ years in the US) and adults with confirming skin prick testing and/or specific IgEs [31].

In 2007 Didier et al. conducted a randomized clinical trial evaluating the dose-response efficacy with a pre-coseasonal Oralair ${ }^{\circledR}$ in 628 patients showing clinical benefits in patients receiving 300 and 500 index of reactivity (IR) 2-4 months before season-start over placebo.
Consequently, the $300 \mathrm{IR}$ dose $(25 \mu \mathrm{g}$ of group 5 grass pollen major allergen) providing a significant reduction in symptoms, was selected as the optimal dose for commercialization [32, 33] (Table 1).

Purethal ${ }^{\circledR}$ Mites (HAL Allergy) is a mite extract mixture used at a concentration of $20,000 \mathrm{AUeq} / \mathrm{ml}(8 \mu \mathrm{g} / \mathrm{ml}$ of Der p1 and $30 \mu \mathrm{g} / \mathrm{ml}$ of Der p2). The administration schedule contemplated a build-up weekly-based phase of increasing doses $(1000,2000,4000,6000,8000$ and 10,000 AUeq), whereas the maintenance phase involved the injection of 10,000 AUeq (Der p1, $4 \mu \mathrm{g}$ of Der p1 and $15 \mu \mathrm{g}$ of Der p2) at monthly intervals. A total of 43 asthmatic children (6-14 years) with mites sensitization were divided in two groups: 23 individuals were treated with subcutaneous Purethal ${ }^{\circledR}$ for 8 months and 20 were the control group. In the active group, there was an improvement in overall asthma classification and severity $(\mathrm{P}<.001$ compared to baseline $)$, a reduction in drugs use and an improvement in quality of life over time during the follow-up [34].

Staloral ${ }^{\circledR} 300$ (SLIT with IR (index of reactivity)-standardized D. pteronyssinus + D. farinae extract (300 IR/ $\mathrm{mL}$ ) manufactured by Stallergenes), has been tested in children aged 6-18 with allergic rhinitis with or without allergic asthma [27]. All patients treated with Staloral ${ }^{\circledR}$ reported improved rhinitis and/or asthma symptoms scores, together with a reduction in the as-needed drug for breakthrough symptoms, with no significant differences in FEV1 and Peak Flow [35] (Table 1).

Another house dust mite sublingual preparation (MK8237) has been approved for patients with HDM-induced ARC with or without coexisting asthma [36] (Table 1).

The product, a standardized allergen extract from D. pteronyssinus and D. farinae 12 SQ-HDM* per oral lyophilisate, has been approved in 2015 by EMA with the brand name of Acarizax ${ }^{\circledR}$ for Europe, Canada and Australia (ALK-Abelló, Hørsholm, Denmark), and it is the first SLIT preparation approved in Europe for the treatment of allergic asthma. In fact, in February 2017 the Global Initiative for Asthma (GINA) for the first time added AIT as a treatment option in its guidelines [22]. Originally approved only for patients $>18$ years old, Acarizax $^{\circledR}$ was recently approved also for adolescent patients with house dust mite-induced allergic rhinitis in Austria, Czech Republic, Denmark, Finland, Italy, the Netherlands, Norway, Poland, Sweden, Slovakia, France and Germany [37].

MK-8237 has been approved in September 2015 by the Japanese Ministry of Health, Labour and Welfare under the name of Miticure ${ }^{\circledR}$ (Torii Pharmaceutical Co., Japan), at a dose of 3300 Japanese Allergen Units (JAU) once a day during the 1st week of treatment and one tablet of Miticure $^{\circledR} 10,000$ JAU once a day from the 2 nd week for 


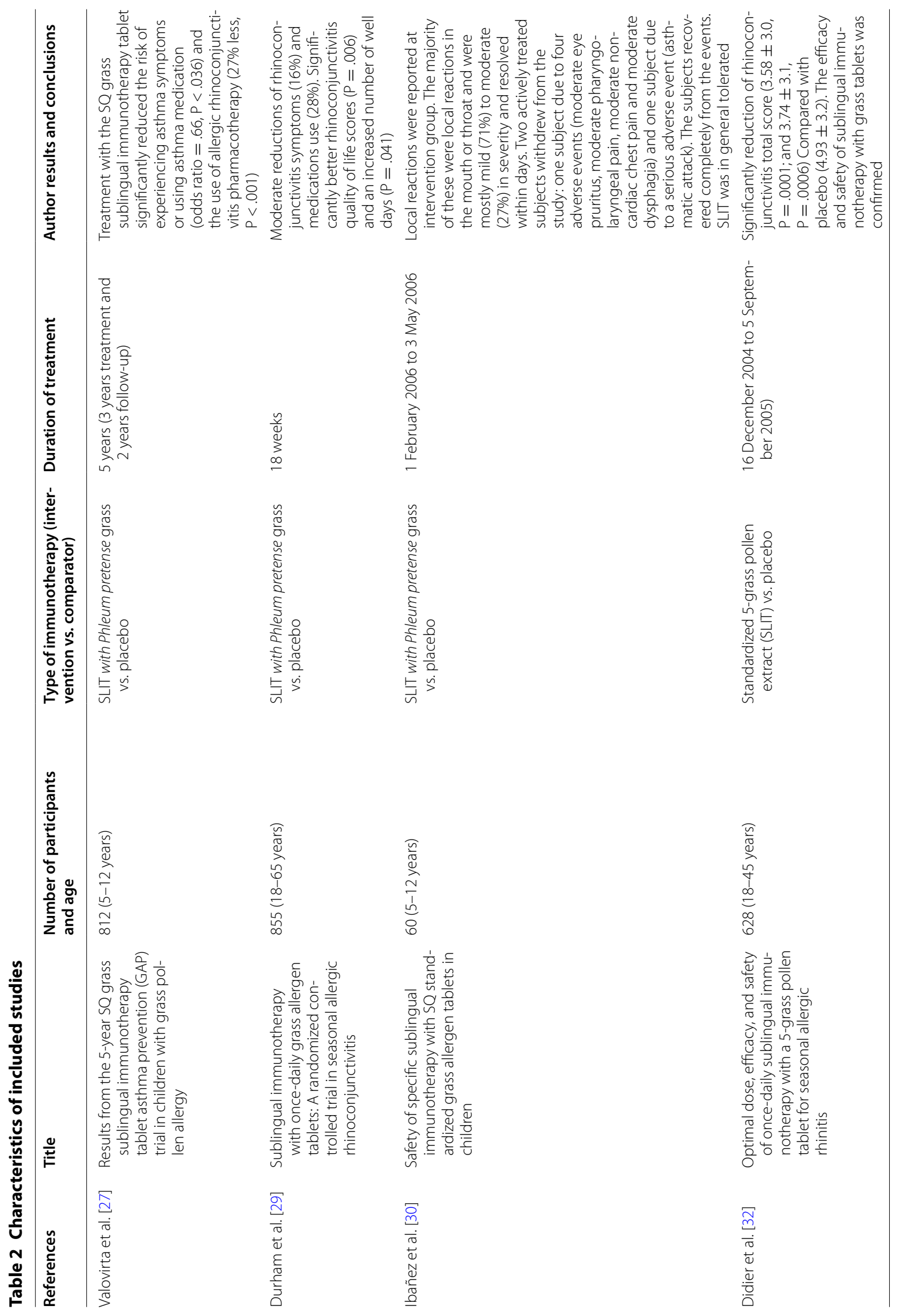




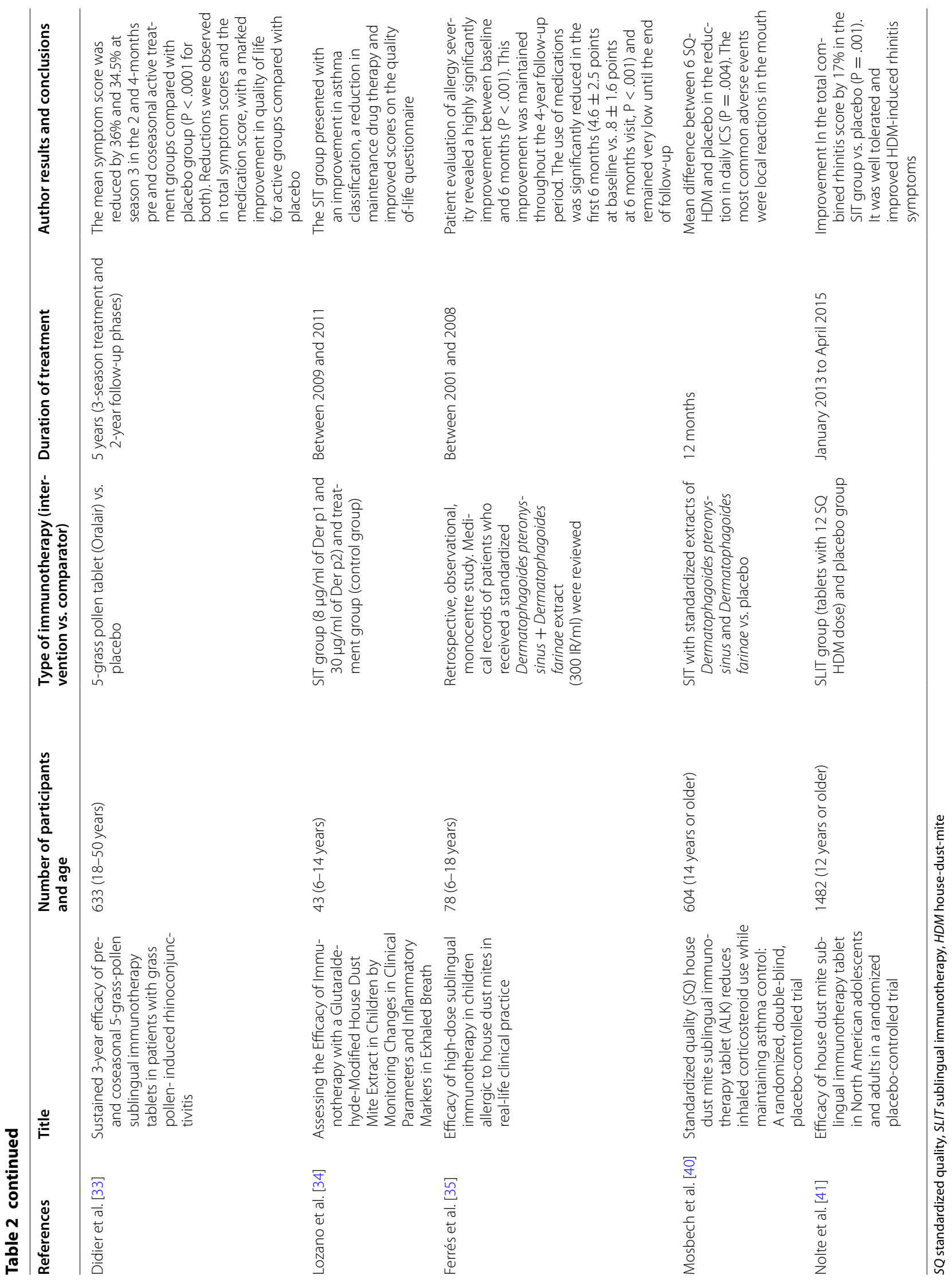


adults and children aged $\geq 12$ years [38] (Table 1). Nowadays, since there are no indications of MK-8237 utilization in children so far, the Company is running a Phase III clinical trial in patients aged 5-11 years [39].

The efficacy of this preparation in asthmatic patients was demonstrated in three clinical trials, two of which included also adolescents.

Mosbech and colleagues, enrolled 604 subjects including adolescents aged $>14$ years with HDM-induced allergic rhinitis and mild-to-moderate asthma. These subjects were randomized in 1:1:1:1 to double-blind daily treatment with active doses $(1,3$, or $6 \mathrm{SQ}-\mathrm{HDM})$ or placebo. The main outcome was a steroid-sparing effect which resulted dose-dependent, higher in subjects receiving 6 SQ HDM-SLIT tablets and that mild-to-moderate HDM-sensitized asthmatic patients could significantly benefit from specific immunotherapy [40]. Furthermore, MK-8237 was evaluated in a recent north American clinical trial (NCT01700192) in adolescents aged 12 years old with HDM-induced allergic rhinoconjunctivitis with or without asthma. This trial confirmed the results obtained by the previous European trials [41].

So far, only one trial to evaluate the clinical efficacy and safety of SLIT in children is still in progress [39]. Thus the need for more robust data in such a population is emergent.

\section{Indications and patients' selection}

Definite indications for the use of AIT in children with asthma are still not fully clarified [16]. Most guidelines [24] agree that AIT is not contraindicated in children with mild to moderate allergic asthma, but also state that asthma must be fully controlled by the standard of care pharmacological treatment, when AIT is prescribed [16, 17, 42, 43]. The recent ARIA guidelines [44] suggest both SCIT and SLIT as a conditional recommendation in allergic asthma, due to the moderate/low quality of evidence. The lack of robust evidence led to a certain grade of opposition to the use of AIT in asthmatics [45]. Indeed, the potential benefits of AIT must be weighed against the risk of adverse effects, the inconvenience and cost of a prolonged course of therapy, as stated by the 2017 Global Initiative for Asthma Report [46] considering also other factors such as poor adherence, clinically non relevant allergens, poly-sensitizations, unavoidable adverse reactions of routine medication, etc [47].

\section{Contraindications}

So far, according to literature, absolute contraindications to AIT involve serious immunologic diseases, major cardiovascular diseases, cancer, chronic infections, lack of compliance and severe psychological disorder [23].
Eosinophilic esophagitis remains an absolute contraindication to SLIT [48].

Relative contraindications include any condition that would reduce the patient's ability to survive a potential systemic allergic reaction [42]. Temporary contraindications are limited to acute infections and, for SLIT, to oral acute inflammation, injury or surgical intervention or acute gastroenteritis $[4,48-50]$.

Well-controlled asthma, independently from its severity, is not an absolute contraindication to AIT [23], whereas uncontrolled asthma is an absolute contraindication due to the risk of serious or even fatal adverse reactions $[23,47,51]$. In this context, the pre-treatment with omalizumab [52] has been suggested as a suitable option to increase the safety. Partially controlled asthma is considered a relative contraindication in the EAACI paper and the German guidelines open to the possibility of use of AIT in these patients [48]. An open area of debate regards well controlled severe asthma, which would not meet the EAACI definition of contraindication, but for which more evidence should become available before recommendations can be issued.

\section{Age of AlT initiation}

The age of 3 years is considered a reasonable contraindication, due to the poor adherence and side effects [53] and age below 5 years is listed as a relative contraindication to AIT in most documents [23, 49,54], although there are positive reports in such age range [55-58]. The reasons for this choice can be found in the limited evidence [59] and for practical reasons, but this issue may deserves more in-depth studies in the perspective of preventive strategies. In fact, a recent position paper by the SIAIP (Società Italiana di Allergologia e Immunologia Pediatrica) [43] recommends the consideration of AIT as a therapeutic option also in preschool age.

\section{Administration regimen, duration of treatment and adherence}

While there is a universal consensus about administration regimen for SCIT, with the maintenance phase given as one injection every 4 weeks, the best SLIT maintenance regimen has not been defined yet [16]. The recommended regimens would favour the pre-coseasonal administration vs. the continuous one, at least for seasonal allergens $[60,61]$.

It is usually recommended that at least 3 years of treatment are necessary to achieve and maintain clinical benefit $[4,48-50]$. A prolonged remission of symptoms is described in many patients [62-66], while others may experience a relapse after discontinuation. As for adults, it is still not clear in pediatric populations whether treatment continuation beyond 3 years leads to persistence of 
clinical benefit after discontinuation [29, 62, 64, 67] and if other factors are involved. The decision about the duration of treatment remains on the clinician judgment, who should take into account the patient clinical response, disease severity, adverse events and patient's preference [42]. In fact, adherence to therapy is an important issue, due to the long duration of treatment [68]. It was shown that $64.6 \%$ of children was unable to complete 3 years of therapy [69]. The reported major factors involved in non-compliance were the cost of treatment, the inconvenience of injections for SCIT and the daily necessity of assumption for SLIT and local reactions [70, 71].

\section{Safety}

Adverse reactions to AIT can be divided in local (limited to the site of administration) [72] and systemic (wheezing, urticaria, anaphylaxis, fatal reactions) [17]. Local reactions consist mainly in local itching and/or edema and, only for SLIT, gastrointestinal complains [46].

Systemic reactions are more frequent in SCIT, for which the reported incidence varies between .06 and $1.01 \%$ [73], whereas with SLIT systemic reactions are reported to occur quite rarely [74].

In a recent prospective European survey [75] involving 762 children and 801 adolescents undergoing AIT, a total of 29 reactions have been reported, of which 23 during SCIT and 6 during SLIT, comprising 3 cases of anaphylaxis, all related to SCIT. Interestingly, the reported cases of anaphylaxis all had a delayed onset $(>2 \mathrm{~h}$ after administration), which highlights an open issue about the correct duration of patient observation after AIT administration, that should last at least $30 \mathrm{~min}$ according to current recommendations $[49,50]$. Sublingual administration appears to be correlated with a much lower risk of systemic reactions. A 2009 observational study in 193 children receiving SLIT [76] reported nearly 500 mild local reactions and only one systemic reaction consisting in a severe asthma attack and a recent review of 80 double-blind placebo-controlled trials concluded that in most studies the incidence of systemic reactions was similar in the treatment group and the placebo group [46].

The occurrence of adverse reactions depends on several factors, including human errors, extracts used, administration route, schedule and the dose administered [52]. Patient-related factors comprise, as already stated, the presence of asthma, especially if uncontrolled [23], polysensitization and grass pollen sensitization [75]. The administered dose seems to be related to systemic reactions only in SCIT, while this does not appear to be dosedependent with SLIT [47].

\section{Conclusions and expert opinion}

Allergen immunotherapy remains a cornerstone option for the treatment of respiratory allergy and for hymenoptera venom allergy with a promising extension to food allergy. AIT especially in the sublingual administration, remains a suitable option in children since it can be easily managed at home, although some aspects still need to be experimentally defined [77]. The possible use of AIT as primary prevention still remains a matter of debate, whereas the clinical efficacy in children is well ascertained, at least for some specific products [78]. Asthma, when well controlled does not represent an absolute contraindication to AIT. There is a consistent evidence that AIT can reduce the risk of asthma onset in sensitized children.

\section{Abbreviations}

AIT: allergen immunotherapy; FDA: Food and Drug Administration; EMA: European Medicines Agency; SCIT: subcutaneous immunotherapy; SLIT: sublingual immunotherapy; AR: allergic rhinitis; AA: allergic asthma; HDM: house-dustmite; GINA: Global Initiative for Asthma; ICS: inhaled corticosteroids; ARC: allergic rhinoconjunctivitis; SQ: standardized quality; SABA: short acting betaagonist; LABA: long acting beta-agonist; ARIA: Allergic Rhinitis and its Impact on Asthma; EAACl: European Academy of Allergy and Clinical Immunology.

\section{Authors' contributions}

$M F$ and FR equally contributed in writing and designing the paper; $L N G M, E H$, $F P, G P, N S$ and GWC guaranteed their expertise in the final writing. All authors read and approved the final manuscript.

\section{Author details}

${ }^{1}$ Allergy \& Respiratory Diseases, DIMI Dept of Internal Medicine, University of Genoa, IRCCS AOU San Martino-IST, Genoa, Italy. ${ }^{2}$ Personalized Medicine, Asthma and Allergy Clinic, Humanitas University and Research Hospital, Via Alessandro Manzoni 113, Rozzano, MI, Italy. ${ }^{3}$ Pediatrics, Allergy and Respiratory Disease, Mater Dei Hospital, Belo Horizonte, Brazil. ${ }^{4}$ Department of Biomedical Sciences, Humanitas University, Rozzano, MI, Italy.

\section{Acknowledgements}

This paper has been partially supported by ARMIA (Associazione Ricerca Malattie Immunologiche e Allergiche) Genova.

\section{Competing interests}

The authors declare that they have no competing interests.

Consent for publication

Not applicable.

Ethics approval and consent to participate Not applicable.

\section{Funding}

GWC has been member of advisory board, speaker, scientific meeting for GSK, Teva, Sanofi, Roche, Novartis, Astra Zeneca. GP was consultant/speaker for ALK-Abellò, AstraZeneca, Lofarma, Novartis, Stallergenes-Greer.

\section{Publisher's Note}

Springer Nature remains neutral with regard to jurisdictional claims in published maps and institutional affiliations.

Received: 11 January 2018 Accepted: 22 February 2018

Published online: 06 March 2018 


\section{References}

1. Passalacqua G, Canonica GW. Allergen immunotherapy: history and future developments. Immunol Allergy Clin North Am. 2016;36(1):1-12. https://doi.org/10.1016/j.iac.2015.08.001 (Epub 2015 Oct 21. Review.)

2. Pajno GB, Fernandez-Rivas M, Arasi S, Roberts G, Akdis CA, Alvaro-Lozano M, EAACI Allergen Immunotherapy Guidelines Group, et al. EAACI Guidelines on allergen immunotherapy: IgE-mediated food allergy. Allergy. 2017. https://doi.org/10.1111/all.13319.

3. Des Roches A, Paradis L, Menardo JL, Bouges S, Daurés JP, Bousquet J. Immunotherapy with a standardized Dermatophagoides pteronyssinus extract. Specific immunotherapy prevents the onset of new sensitizations in children. J Allergy Clin Immunol. 1997;99(4):450-3.

4. Canonica GW, Cox L, Pawankar R, Baena-Cagnani CE, Blaiss M, Bonini S, et al. Sublingual immunotherapy: World Allergy Organization position paper 2013 update. World Allergy Organ J. 2014. https://doi. org/10.1186/1939-4551-7-6.

5. Ferrando M, Bagnasco D, Varricchi G, Bernardi S, Bragantini A, Passalacqua $\mathrm{G}$, et al. Personalized medicine in allergy. Allergy Asthma Immunol Res. 2017. https://doi.org/10.4168/aair.2017.9.1.15.

6. Ferrando M, Bagnasco D, Passalacqua G, Puggioni F, Varricchi G, Canonica GW. New suggestions in sublingual immunotherapy for house dust miterelated allergic diseases. Curr Pharm Biotechnol. 2017. https://doi.org/10. 2174/1389201018666170417103316.

7. Noon L. Prophylactic inoculation against hay fever. b.c. cantab., f.r.c.s. eng. The Lancet. (From the Laboratory of the Department for Therapeutic Inoculation, St. Mary's Hospital.). 1911. http://dx.doi.org/10.1016/ S0140-6736(00)78276-6.

8. Passalacqua G, Albano M, Fregonese L, et al. Randomised controlled trial of local allergoid immunotherapy on allergic inflammation in miteinduced rhinoconjunctivitis. Lancet. 1998;351(9103):629-32.

9. Drachenberg KJ, Urban E, Pröll S, Woroniecki SR. Sublingual specific immunotherapy for adults and children: a post-marketing surveillance study. Allergol Immunopathol (Madr). 2004;32(2):76-81.

10. Passalacqua G, Pasquali M, Ariano R, Lombardi C, Giardini A, Baiardini I, et al. Randomized double-blind controlled study with sublingual carbamylated allergoid immunotherapy in mild rhinitis due to mites. Allergy. 2006;61(7):849-54

11. Marogna M, Colombo F, Cerra C, Bruno M, Massolo A, Canonica GW, et al. The clinical efficacy of a sublingual monomeric allergoid at different maintenance doses: a randomized controlled trial. Int J Immunopathol Pharmacol. 2010;23(3):937-45.

12. Gammeri E, Arena A, D'Anneo R, La Grutta S. Safety and tolerability of ultra-rush (20 minutes) sublingual immunotherapy in patients with allergic rhinitis and/or asthma. Allergol Immunopathol (Madr). 2005;33(4):221-3.

13. Tripodi S, Di Rienzo Businco A, Benincori N, Scala G, Pingitore G. Safety and tolerability of ultra-rush induction, less than one hour, of sublingual immunotherapy in children. Int Arch Allergy Immunol. 2006;139(2):149-

\section{2 (Epub 2005 Dec 22).}

14. Rosewich M, Schulze J, Fischer von Weikersthal-Drachenberg KJ, Zielen S. Ultra-short course immunotherapy in children and adolescents during a 3-yrs post-marketing surveillance study. Pediatr Allergy Immunol. 2010;21(1 Pt 2):e185-9. https://doi.org/10.1111/j.1399-3038.2009.00953.x (Epub 2009 Dec 8)

15. Bachert C, Larché M, Bonini S, Canonica GW, Kündig T, Larenas-Linnemann D, et al. Allergen immunotherapy on the way to product-based evaluation-a WAO statement. World Allergy Organ J. 2015;8(1):29. https:// doi.org/10.1186/s40413-015-0078-8 (eCollection 2015)

16. Comberiati P, Marseglia GL, Barberi S, Passalacqua G, Peroni DG. Allergenspecific immunotherapy for respiratory allergy in children: unmet needs and future goals. J Allergy Clin Immunol Pract. 2017. https://doi. org/10.1016/j.jaip.2017.01.024.

17. Abramson MJ, Puy RM, Weiner JM. Injection allergen immunotherapy for asthma. Cochrane Database Syst Rev. 2010. https://doi. org/10.1002/14651858.CD001186.pub2.

18. Olaguibel JM, Alvarez Puebla MJ. Efficacy of sublingual allergen vaccination for respiratory allergy in children. Conclusions from one metanalysis. J Investig Allergol Clin Immunol. 2005;15:9-16.
19. Penagos M, Passalacqua G, Compalati E, Baena-Cagnani CE, Orozco S, Pedroza A, et al. Meta-analysis of the efficacy of sublingual immunotherapy in the treatment of allergic asthma in pediatric patients, 3 to 18 years of age. Chest. 2008;133:599-609.

20. Bufe A, Eberle P, Franke-Beckmann E, Funk J, Kimming M, Klimek $\mathrm{L}$, et al. Safety and efficacy in children of an SQ-standardized grass allergen tablet for sublingual immunotherapy. J Allergy Clin Immunol. 2009;123:167e7-173e7.

21. Wahn U, Tabar A, Kuna P, Halken S, Montagut A, Beaumont O, et al. Efficacy and safety of 5-grass-pollen sublingual immunotherapy tablets in pediatric allergic rhinoconjunctivitis. J Allergy Clin Immunol. 2009;123:160e3-166e3.

22. http://ginasthma.org/2017-gina-report-global-strategy-for-asthmamanagement-and-prevention/. Accessed 24 Nov 2017.

23. Pitsios C, Demoly P, Bilo MB, Gerth van Wijk R, Pfaar O, Sturm GJ, et al. Clinical contraindications to allergen immunotherapy: an EAACl position paper. Allergy. 2015. https://doi.org/10.1111/all.12638.

24. Halken S, Larenas-Linnemann D, Roberts G, Calderón MA, Angier E, Pfaar $\mathrm{O}$, et al. EAACI guidelines on allergen immunotherapy: prevention of allergy. Pediatr Allergy Immunol. 2017. https://doi.org/10.1111/pai.12807.

25. Di Lorenzo G, Leto-Barone MS, La Piana S, Plaia A, Di Bona D. The effect of allergen immunotherapy in the onset of new sensitizations: a metaanalysis. Int Forum Allergy Rhinol. 2017;7(7):660-9.

26. Dhami S, Kakourou A, Asamoah F, Agache I, Lau S, Jutel M, Muraro A, et al. Allergen immunotherapy for allergic asthma: a systematic review and meta-analysis. Allergy. 2017. https://doi.org/10.1111/all.13208.

27. Valovirta E, Petersen TH, Piotrowska T, Laursen MK, Andersen JS, Sørensen $\mathrm{HF}$, et al. GAP investigators. Results from the 5-year SQ grass sublingual immunotherapy tablet asthma prevention (GAP) trial in children with grass pollen allergy. J Allergy Clin Immunol. 2017. https://doi. org/10.1016/j.jaci.2017.06.014.

28. Canonica GW, Bachert C, Hellings P, Ryan D, Valovirta E, Wickman M, et al. Allergen immunotherapy (AIT): a prototype of precision medicine. World Allergy Organ J. 2015;8(1):31. https://doi.org/10.1186/s40413-015-0079-7 (eCollection 2015).

29. Durham SR, Yang WH, Pedersen MR, Johansen N, Rak S. Sublingual immunotherapy with once daily grass allergen tablet: a randomized controlled trial in seasonal allergic rhinoconjunctivitis. J. Allergy Clin Immunol. 2006;117(4):802-9.

30. Ibañez MD, Kaiser F, Knecht R, Armentia A, Schöpfer H, Tholstrup B, et al. Safety of specific sublingual immunotherapy with SQ standardized grass allergen tablets in children. Pediatr Allergy Immunol. 2007;18(6):516-22.

31. Larenas-Linnemann D. How does the efficacy and safety of Oralair $\left({ }^{\circledR}\right)$ compare to other products on the market? Ther Clin Risk Manag. 2016. https://doi.org/10.2147/TCRM.S70363.

32. Didier A, Malling HJ, Worm M, Horak F, Jäger S, Montagut A, et al. Optimal dose, efficacy, and safety of once-daily sublingual immunotherapy with a 5-grass pollen tablet for seasonal allergic rhinitis. J Allergy Clin Immunol. 2007;120(6):1338-45.

33. Didier A, Worm M, Horak F, Sussman G, de Beaumont O, Le Gall M, et al. Sustained 3-year efficacy of pre-and coseasonal 5-grass-pollen sublingual immunotherapy tablets in patients with grass pollen-induced rhinoconjunctivitis. J Allergy Clin Immunol. 2011;128(3):559-66.

34. Lozano J, Cruz MJ, Piquer M, Giner MT, Plaza AM. Assessing the efficacy of immunotherapy with a glutaraldehyde-modified house dust mite extract in children by monitoring changes in clinical parameters and inflammatory markers in exhaled breath. Int Arch Allergy Immunol. 2014;165(2):140-7. https://doi.org/10.1159/000368832 (Epub 2014 Dec 2)

35. Ferrés J, Justicia JL, García MP, Muñoz-Tudurí M, Alvà V. Efficacy of highdose sublingual immunotherapy in children allergic to house dust mites in real-life clinical practice. Allergol Immunopathol. 2011. https://doi. org/10.1016/j.aller.2010.01.008.

36. Ferrando $M$, Bagnasco D, Passalacqua G, Puggioni F, Varricchi G, Canonica GW. New suggestions in sublingual immunotherapy for house dust miterelated allergic diseases. Curr Pharm Biotechnol. 2017:18(5):378-83.

37. ALK; 2017. http://ir.alk.net/releasedetail.cfm?releaseid $=1021411$. Accessed 21 Nov 2017 
38. ALK; 2017 http://ir.alk.net/releasedetail.cfm?releaseid=944496. Accessed 21 Nov 2017

39. ALK. 2017; http://ir.alk.net/releases.cfm. Accessed 03 Nov 2017.

40. Mosbech H, Deckelmann R, de Blay F, Pastorello EA, Trebas-Pietras E, Andres LP, et al. Standardized quality (SQ) house dust mite sublingual immunotherapy tablet (ALK) reduces inhaled corticosteroid use while maintaining asthma control: a randomized, double-blind, placebo-controlled trial. J Allergy Clin Immunol. 2014;134(3):568-75.

41. Nolte H, Bernstein DI, Nelson HS, Kleine-Tebbe J, Sussman GL, Seitzberg $D$, et al. Efficacy of house dust mite sublingual immunotherapy tablet in North American adolescents and adults in a randomized, placebocontrolled trial. J Allergy Clin Immunol. 2016. https://doi.org/10.1016/j. jaci.2016.06.044.

42. Joint Task Force on Practice Parameters, American Academy of Allergy, Asthma and Immunology, American College of Allergy, Asthma and Immunology, Joint Council of Allergy, et al. Allergen immunotherapy: a practice parameter second update. J Allergy Clin Immunol. 2007. https:// doi.org/10.1016/j.jaci.2007.06.019.

43. Pajno GB, Bernardini R, Peroni D, Arasi S, Martelli A, Landi M, et al. Allergen-specific Immunotherapy panel of the Italian Society of Pediatric Allergy and Immunology (SIAIP). Clinical practice recommendations for allergen-specific immunotherapy in children: the Italian consensus report. Ital J Pediatr. 2017. https://doi.org/10.1186/s13052-016-0315-y.

44. Bousquet J, Schunemann HJ, Samolinski B, Demoly P, Baena-Cagnani CE, Bachert $C$, et al. Allergic rhinitis and its impact on asthma (ARIA): achievements in 10 years and future needs. J Allergy Clin Immunol. 2012. https:// doi.org/10.1016/j.jaci.2012.07.053.

45. Arshad SH. An update on allergen immunotherapy. Clin Med. 2016. https://doi.org/10.7861/clinmedicine.16-6-584.

46. Passalacqua G, Nowak-Węgrzyn A, Canonica GW. Local side effects of sublingual and oral immunotherapy. J Allergy Clin Immunol Pract. 2017. https://doi.org/10.1016/j.jaip.2016.06.020.

47. Calderon MA, Larenas D, Kleine-Tebbe J, Jacobsen L, Passalacqua G, Eng PA, et al. European Academy of Allergy and Clinical Immunology task force report on 'dose-response relationship in allergen-specific immunotherapy.' Allergy. 2011. https://doi.org/10.1111/j.1398-9995.2011.02669.x.

48. Pfaar O, Bachert C, Bufe A, Buhl R, Ebner C, Eng P, et al. Guideline on allergen-specific immunotherapy in IgE-mediated allergic diseases: S2K Guideline of the German Society for Allergology and Clinical Immunology (DGAKI), the Society for Pediatric Allergy and Environmental Medicine (GPA), the Medical Association of German Allergologists (AeDA), the Austrian Society for Allergy and Immunology (ÖGAl), the Swiss Society for Allergy and Immunology (SGAI), the German Society of Dermatology (DDG), the German Society of Oto- Rhino-Laryngology, Head and Neck Surgery (DGHNO-KHC), the German Society of Pediatrics and Adolescent Medicine (DGKJ), the Society for Pediatric Pneumology (GPP), the German Respiratory Society (DGP), the German Association of ENT Surgeons (BV-HNO), the Professional Federation of Paediatricians and Youth Doctors (BVKJ), the Federal Association of Pulmonologists (BDP) and the German Dermatologists Association (BVDD). Allergo J Int. 2014:23(8):282-319.

49. Jutel M, Agache I, Bonini S, Burks AW, Calderon M, Canonica W, et al. International consensus on allergy immunotherapy. J Allergy Clin Immunol. 2015. https://doi.org/10.1016/j.jaci.2015.04.047.

50. Cox L, Nelson H, Lockey R, Calabria C, Chacko T, Finegold I, et al. Allergen immunotherapy: a practice parameter third update. J Allergy Clin Immunol. 2011; https://doi.org/10.1016/j.jaci.2010.09.034. Erratum in: J Allergy Clin Immunol. 2011;127(3):840.

51. Scadding GW, Calderon MA, Bellido V, Koed GK, Nielsen NC, Lund K, et al. Optimisation of grass pollen nasal allergen challenge for assessment of clinical and immunological outcomes. J Immunol Methods. 2012. https:// doi.org/10.1016/j.jim.2012.06.013.

52. Yukselen A. Allergen-specific immunotherapy in pediatric allergic asthma. Asia Pac Allergy J. 2016. https://doi.org/10.5415/apallergy.2016.6.3.139.

53. Pajno GB, Caminiti L, Crisafulli G, Barberi S, Landi M, Aversa T, et al. Adherence to sublingual immunotherapy in preschool children. Pediatr Allergy Immunol. 2012;23(7):688-9.

54. Zuberbier T, Bachert C, Bousquet PJ, Passalacqua G, Walter Canonica G, Merk $\mathrm{H}$, et al. GA(2) LEN/EAACl pocket guide for allergen-specific immunotherapy for allergic rhinitis and asthma. Allergy. 2010. https://doi. org/10.1111/j.1398-9995.2010.02474.x.
55. Eng PA, Borer-Reinhold M, Heijnen IA, Gnehm HP. Twelve-year follow-up after discontinuation of preseasonal grass pollen immunotherapy in childhood. Allergy. 2006;61(2):198-201.

56. Cantani A, Arcese G, Lucenti P, Gagliesi D, Bartolucci M. A three-year prospective study of specific immunotherapy to inhalant allergens: evidence of safety and efficacy in 300 children with allergic asthma. J Invest Allergol Clin Immunol. 1997;7:90-7.

57. Fiocchi A, Pajno G, La Grutta S, Pezzuto F, Incorvaia C, Sensi L, et al. Safety of sublingual-swallow immunotherapy in children aged 3 to 7 years. Ann Allergy Asthma Immunol. 2005;95(3):254-8.

58. Agostinis F, Tellarini L, Canonica GW, Falagiani P, Passalacqua G. Safety of sublingual immunotherapy with a monomeric allergoid in very young children. Allergy. 2005;60(1):133.

59. Finegold I. Immunotherapy: when to initiate treatment in children. Allergy Asthma Proc. 2007. https://doi.org/10.2500/aap.2007.28.3053.

60. Pajno GB, Caminiti L, Crisafulli G, Vita D, Valenzise M, De Luca R, et al. Direct comparison between continuous and coseasonal regimen for sublingual immunotherapy in children with grass allergy: a randomized controlled study. Pediatr Allergy Immunol. 2011. https://doi. org/10.1111/j.1399-3038.2011.01196.x.

61. Stelmach I, Kaluzinska-Parzyszek I, Jerzynska J, Stelmach P, Stelmach W, Majak P. Comparative effect of pre-coseasonal and continuous grass sublingual immunotherapy in children. Allergy. 2012. https://doi. org/10.1111/j.1398-9995.2011.02758.x.

62. Marogna M, Spadolini I, Massolo A, Canonica GW, Passalacqua G. Longlasting effects of sublingual immunotherapy according to its duration: a 15-year prospective study. J Allergy Clin Immunol. 2010. https://doi. org/10.1016/j.jaci.2010.08.030.

63. Karakoc-Aydiner E, Eifan AO, Baris S, Gunay E, Akturk E, Akkoc T, et al. Long-term effect of sublingual and subcutaneous immunotherapy in dust mite-allergic children with asthma/rhinitis: a 3-year prospective randomized controlled trial. J Investig Allergol Clin Immunol. 2015; 25(5):334-42. Erratum in: J Investig Allergol Clin Immunol. (2016); 26(2):144.

64. Stelmach I, Sobocińska A, Majak P, Smejda K, Jerzyńska J, Stelmach W. Comparison of the long-term efficacy of 3-and 5-year house dust mite allergen immunotherapy. Ann Allergy Asthma Immunol. 2012;109(4):274-8. https://doi.org/10.1016/j.anai.2012.07.015.

65. Ozdemir C, Yazi D, Gocmen I, Yesil O, Aydogan M, Semic-Jusufagic A, et al. Efficacy of long-term sublingual immunotherapy as an adjunct to pharma-cotherapy in house dust mite-allergic children with asthma. Pediatr Allergy Immunol. 2007. https://doi. org/10.1111/j.1399-3038.2007.00549.x.

66. Arroabarren E, Tabar Al, Echechipía S, Cambra K, García BE, Alvarez-Puebla MJ. Optimal duration of allergen immunotherapy in children with dust mite respiratory allergy. Pediatr Allergy Immunol. 2015. https://doi. org/10.1111/pai.12296.

67. Frati F, Dell'Albani I, Incorvaia C. Long-term efficacy of allergen immunotherapy: what do we expect? Immunotherapy. 2013. https://doi. org/10.2217/imt. 12.154

68. Canonica GW, Compalati E. Year in review: allergen immunotherapy. Ann Allergy Asthma Immunol. 2015. https://doi.org/10.1016/j. anai.2014.12.024.

69. Anolik R, Schwartz AM, Sajjan S, Allen-Ramey F. Patient initiation and persistence with allergen immunotherapy. Ann Allergy Asthma Immunol. 2014. https://doi.org/10.1016/j.anai.2014.04.008.

70. Nelson HS, Makatsori M, Calderon MA. Subcutaneous immunotherapy and sublingual immunotherapy: comparative efficacy, current and potential indications, and warnings_-United States versus Europe. Immunol Allergy Clin North Am. 2016. https://doi.org/10.1016/j.iac.2015.08.005.

71. Jutel M, Bartkowiak-Emeryk M, Bręborowicz A, Cichocka-Jarosz E, Emeryk A, Gawlik R, et al. Sublingual immunotherapy (SLIT)—indications, mechanism, and efficacy. Ann Agric Environ Med. 2016. https://doi. org/10.5604/12321966.1196851.

72. Passalacqua G, Baena-Cagnani CE, Bousquet J, Canonica GW, Casale TB, Cox L, et al. Grading local side effects of sublingual immunotherapy for respiratory allergy: speaking the same language. J Allergy Clin Immunol. 2013. https://doi.org/10.1016/j.jaci.2013.03.039.

73. Yukselen A, Kendirli SG. Role of immunotherapy in the treatment of allergic asthma. World J Clin Cases. 2014. https://doi.org/10.12998/wjcc. v2.i12.859. 
74. Passalacqua G, Nowak-Werzgryn A, Canonica GW. The safety of oral and sublingual immunotherapy. J Allergy Clin Immunol Pract. 2017;5:13-21.

75. Rodríguez Del Río P, Vidal C, Just J, Tabar Al, Sanchez-Machin I, Eberle $P$, et al. The European survey on adverse systemic reactions in allergen immu-notherapy (EASSI): a paediatric assessment. Pediatr Allergy Immu nol. 2017. https://doi.org/10.1111/pai.12660)

76. Seidenberg J, Pajno GB, Bauer CP, La Grutta S, Sieber J. Safety and tolerability of seasonal ultra-rush, high-dose sublingual-swallow immunotherapy in allergic rhinitis to grass and tree pollens: an observationa study in 193 children and adolescents. J Investig Allergol Clin Immunol. 2009:19(2):125-31.
77. Comberiati P, Marseglia G, Barberi S, Passalacqua G, Peroni D. Allergenspecific immunotherapy for respiratory allergy in children: unmet needs and future goals. JACI Practice. 2017;5:946-50.

78. Nurmatov U, Dhami S, Arasi S, Roberts G, Pfaar O, Muraro A, et al. Allergen immunotherapy for allergic rhinoconjunctivitis: a systematic overview of systematic reviews. Clin Transl Allergy. 2017;8(7):24. https://doi. org/10.1186/s13601-017-0159-6 (eCollection 2017. Review.)

\section{Submit your next manuscript to BioMed Central and we will help you at every step:}

- We accept pre-submission inquiries

- Our selector tool helps you to find the most relevant journal

- We provide round the clock customer support

- Convenient online submission

- Thorough peer review

- Inclusion in PubMed and all major indexing services

- Maximum visibility for your research

Submit your manuscript at www.biomedcentral com/submit 